\title{
Estimated glomerular filtration rate as an independent predictor of atherosclerotic vascular disease in older women
}

\author{
Joshua R Lewis ${ }^{1,2^{*}}$, Wai Lim ${ }^{1,3}$, Satvinder S Dhaliwal ${ }^{4}$, Kun Zhu ${ }^{1,2}$, Ee Mun Lim ${ }^{1,2}$, Peter L Thompson ${ }^{5}$ \\ and Richard L Prince ${ }^{1,2}$
}

\begin{abstract}
Background: Estimated glomerular filtration rate (eGFR) levels have been shown to predict atherosclerotic vascular disease hospitalization and mortality. We sought to investigate the role of renal function in the prediction of 10year atherosclerotic vascular hospitalization and deaths in an unselected population of elderly women in and compared these predictions to Framingham equations.

Methods: Complete 10-year verified mortality and hospitalization discharge records for atherosclerotic vascular disease was collected for a prospective study of 1,239 unselected female subject's $\geq 70$ from the Calcium Intake Fracture Outcome Study (CAIFOS) with 10 years of follow-up. eGFR was compared to the current Framingham risk scores.

Results: The eGFR at baseline using the Modification of Diet in Renal Disease Study (MDRD) equation was $65.2 \pm 14.5 \mathrm{~mL} / \mathrm{min} / 1.73 \mathrm{~m}^{2}$ and $66.3 \pm 13.5 \mathrm{~mL} / \mathrm{min} / 1.73 \mathrm{~m}^{2}$ using the Chronic Kidney Disease EPIdemiology (CKDEPI) equation. Over 10 years 30\% of participants sustained an ASVD hospitalization or death. For every standard deviation (SD) reduction in eGFR using MDRD the odds ratio (OR) for ASVD hospitalization and deaths increased by 1.34 (1.18-1.53), $\mathrm{P}<0.001$ and 1.31 (1.14-1.50), $\mathrm{P}<0.001$ in a model adjusted for Framingham 10-year general cardiovascular risk. Addition of eGFR by the MDRD equation to Framingham risk factors improved the net reclassification index by 5.9\%, $\mathrm{P}=0.018$ and the integrated discrimination improvement by $0.010 \pm 0.003, P<0.001$ Similar results were seen using the CKD-EPI equation.

Conclusion: Estimated glomerular filtration rate predicts ASVD outcomes independently of Framingham risk score predictions in elderly women and improves clinical prediction particularly of early ASVD.
\end{abstract}

\section{Background}

Atherosclerotic vascular disease (ASVD) remains a leading cause of morbidity and mortality. The development of equations to estimate renal function using age and serum creatinine has shown that estimated glomerular filtration rate (eGFR) is an important predictor of clinical ASVD outcomes, especially mortality, when eGFR falls below $60 \mathrm{ml} / \mathrm{min} / 1.73 \mathrm{~m}^{2}[1-3]$ and is associated with all cause and cardiovascular mortality in general

\footnotetext{
*Correspondence: joshua.lewis@uwa.edu.au

'University of Western Australia, School of Medicine and Pharmacology, Sir Charles Gairdner Hospital Unit, Perth, Australia

2Department of Endocrinology and Diabetes, Sir Charles Gairdner Hospital, Perth, Australia

Full list of author information is available at the end of the article
}

population cohorts [4]. Many studies have been restricted to study of patients with eGFR below $60 \mathrm{ml} / \mathrm{min} / 1.73 \mathrm{~m}^{2}$ compared to above $60 \mathrm{ml} / \mathrm{min} / 1.73 \mathrm{~m}^{2}$ [5-9]. However the effects of earlier stages of renal function deterioration on ASVD outcomes have been less well studied particularly in the elderly [10]. Thus there is uncertainty as to whether mild renal dysfunction may have adverse cardiovascular effects independent of known risk factors in this population.

Two methods of calculating eGFR have been developed the "175" Modification of Diet in Renal Disease (MDRD) equation [11] and the CKD-EPI equation [2]. In middle aged populations comparison of the MDRD equation to the CKD-EPI equation to predict mortality

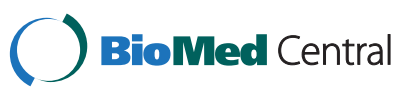


concluded that the CKD-EPI equation showed some advantages over the MDRD equation [2,12,13].

The study design employed used both the revised MDRD and the CKD-EPI equations to examine the relationship of eGFR to atherosclerotic vascular disease in unselected elderly women using complete adjudicated hospital record discharge data from the Western Australian Data Linkage System. In addition the eGFR calculations were compared to the Framingham general cardiovascular risk model.

\section{Methods}

\section{Study population}

The participants were recruited in 1998 and followed for 10 years. At baseline they entered a 5-year prospective, randomized, controlled trial of oral calcium supplements to prevent osteoporotic fractures [14]. The participants were ambulant and did not have any medical conditions likely to influence 5-year survival. They were only excluded if they were receiving bone-active agent, including hormone replacement therapy. Participants were similar in terms of baseline disease burden and medications compared to the whole population of this age but they were more likely to be from higher socio-economic groups [14]. They were subsequently asked to enter a 5year follow-up study of ageing.

They were recruited from the Western Australian general population of women aged over 70 years by mail using the electoral roll a requirement of citizenship. Over $99 \%$ of Australians of this age are registered on the roll. Of the 5,586 women who responded to a letter inviting participation 1,510 women were willing and eligible and of these 1,500 women were recruited for the study. In the first 5 years of the study participants received $1.2 \mathrm{~g}$ of elemental calcium as calcium carbonate daily or a matched placebo. The Human Ethics Committee of the University of Western Australia approved the study.

\section{Renal function assessment}

Baseline renal function was determined in 1,239 women. Serum was collected after an overnight fast and serum creatinine analysed in 2005 using an isotope dilution mass spectrometry (IDMS) traceable Jaffe kinetic assay for creatinine on a Hitachi 917 analyzer (Roche Diagnostics GmbH, Mannheim Germany). The estimated GFR calculated in $\mathrm{mL} / \mathrm{min} / 1.73 \mathrm{~m}^{2}$ using the revised " 175 " MDRD study equation was; 175 (standardized serum creatinine $(\mathrm{Scr})$ in $\mathrm{mg} / \mathrm{dL})^{-1.154} \times(\text { Age })^{-0.203} \times 0.742$ with creatinine values entered in $\mathrm{mg} / \mathrm{dL}$ into the equation $[11,15,16]$. The estimated GFR calculated using the CKD-EPI equations was; $\mathrm{Scr} \leq 0.7 \mathrm{mg} / \mathrm{dL}=144 \times(\mathrm{Scr} /$ $0.7)^{-0.329} \times(0.993)$ Age or $\mathrm{Scr}>0.7 \mathrm{mg} / \mathrm{dL}=144 \times(\mathrm{Scr} /$ $0.7)^{-1.209} \times(0.993)$ Age with creatinine values entered in $\mathrm{mg} / \mathrm{dL}$ into the equations [2]. Estimated GFR was separated into Chronic Kidney Disease (CKD) categories as defined by the kidney disease outcomes quality initiative (K/DOQI) classification [17].

\section{Framingham risk score}

The 10-year Framingham general cardiovascular disease risk score was calculated using age, previous diabetes, body mass index, current smoking status and the untreated systolic blood pressure using the equation and estimated regression coefficients developed by D'Agostino et al. 2008 [18].

The Framingham risk score (FRS) equation was;

$\mathrm{FRS}=1-0.94833^{\exp \left(2.72107^{*} \ln (\text { Age })+0.51125^{*} \ln (B M I)+2.81291^{\prime \prime} \ln \right.}$ (SBP)+0.61868"(Currentsmoker) $+0.77763^{\prime \prime}$ (Diabetes)-26.0145).

The risk scores were then confirmed using the online calculator prepared by R.B. D'Agostino and M.J. Pencina based on the publication by D'Agostino et al. [18].

\section{Baseline ASVD risk assessment}

Previous atherosclerotic vascular disease was determined from the complete hospital discharge data from 19801998 and were defined using diagnosis codes from the International Classification of Diseases, Injuries and Causes of Death Clinical Modification (ICD-9-CM) [19]. These codes included: ischemic heart disease (ICD-9CM codes 410-414); heart failure (ICD-9-CM code 428); cerebrovascular disease excluding hemorrhage (ICD-9-CM codes 433-438); and peripheral arterial disease (ICD-9-CM codes 440-444). The participants provided their previous medical history and current medications verified by their General Practitioner. These data were coded using the International Classification of Primary Care - Plus (ICPC-Plus) method [20]. The coding methodology allows aggregation of different terms for similar pathologic entities as defined by the ICD-10 coding system. These data were then used to determine the presence of diabetes at baseline.

At baseline weight was assessed using digital scales with participants wearing light clothes and no shoes, height was assessed using a stadiometer and the body mass index was calculated in $\mathrm{kg} / \mathrm{m}^{2}$. Blood pressure was measured in 1,205 participants on the right arm with a mercury column Manometer using an adult cuff after the patient had been seated and resting for at least 5 minutes, the average of 3 such measurements was obtained.

\section{Incident ASVD outcome assessment}

The primary outcome was an atherosclerotic vascular disease event causing hospitalization or death. First-time atherosclerotic hospitalizations were retrieved from the Western Australian Data Linkage System (WADLS) for each of the study participants from 1998 until 10 years after their baseline visit. WADLS provides a complete 
validated record of every participant's primary diagnosis at hospital discharge using coded data form all hospitals in Western Australia. Cause of death was retrieved from the coded death certificate using information in Parts 1 and 2 of the death certificate, all diagnosis text fields from the death certificate were used to ascertain the cause(s) of deaths where these data were not yet available from the WADLS. Atherosclerotic events were defined using primary diagnosis codes from the International Classification of Diseases, Injuries and Causes of Death Clinical Modification (ICD-9-CM) [19] and the International Statistical Classification of Diseases and Related Health Problems, $10^{\text {th }}$ Revision, Australian Modification (ICD-10- AM) [21]. These codes included: ischemic heart disease (ICD-9-CM codes 410-414 and ICD-10-AM codes I20-I25); heart failure (ICD-9-CM code 428 and ICD-10-AM code I50); cerebrovascular disease excluding hemorrhage (ICD-9-CM codes 433438 and ICD-10-AM codes I63-69, G45.9); and peripheral arterial disease (ICD-9-CM codes 440-444 and ICD-10-AM codes I70-74).

\section{Statistical analysis}

The primary outcome was the odds ratio of the time to first atherosclerotic vascular hospitalization or death up to $\leq 10$ years after the baseline visit. Covariates were entered into the model as continuous variables with the exception of current smoking and diabetes, which were entered as dichotomous $(\mathrm{y} / \mathrm{n})$ variables. All continuous variables were naturally logarithmically transformed to improve discrimination and calibration of the models and to minimize the influence of extreme observations. No interactions between baseline confounders were detected. The effect of eGFR on reclassification of risk was assessed using net reclassification improvement and integrated discrimination improvement [22,23]. Using the Framingham risk factors participants were classified into three 10-year risk categories of ASVD, low $(<15 \%)$, intermediate $(15 \%-30 \%)$ or high $(\geq 30 \%)$ for ASVD hospitalizations and deaths. These risk categories are based on the median predicted risk by Framingham risk factors (30\%). The participants were then reclassified into new risk categories with the addition of eGFR to the model and the net reclassification improvement (NRI) and integrated discrimination improvement (IDI) were calculated. Results are presented as odds ratio (OR) and associated $95 \%$ confidence intervals. $P$ values less than 0.05 in two tailed testing were considered statistically significant. The data was analysed using SPSS (version 15; SPSS Inc., Chicago, IL), STATA (version 11 StataCorp LP, College Station, TX) and SAS (Version 9, SAS Institute Inc., Chicago, IL).

\section{Results}

The mean age of the 1,239 participants was $75.2 \pm 2.7$ years and the mean eGFR by the MDRD and the CKD-EPI equations was $65.2 \pm 14.5$ and $66.3 \pm 13.5 \mathrm{~mL} / \mathrm{min} / 1.73 \mathrm{~m}^{2}$ respectively, $63 \%$ and $66 \%$ of the participants had an eGFR $\geq 60 \mathrm{~mL} / \mathrm{min} / 1.73 \mathrm{~m}^{2}$ by the MDRD and CKD-EPI equations. The baseline characteristics of the 1,239 participants are shown in Table 1. Participants who sustained an ASVD event over the 10 years of the study had lower baseline values for eGFR by the MDRD and the CKD-EPI equations and higher values for age, body mass index, prevalent diabetes, systolic blood pressure and previous history of ASVD.

The relationship between each individual's atherosclerotic vascular disease hospitalizations and mortality outcomes and their eGFR, total Framingham score and each component of that score are shown in Table 2. As expected smoking, diabetes and prevalent ASVD showed the largest effects, however because of small numbers current smoking was not significant. eGFR by both methods compared well to the other continuous risk factors systolic blood pressure and BMI. The Kaplan Meir data for ASVD hospitalization and death by categories of

Table 1 Baseline characteristics of the total cohort and those with and without subsequent atherosclerotic vascular disease (ASVD) hospitalization and mortality

\begin{tabular}{|c|c|c|c|c|}
\hline Baseline Characteristics & All participants $(n=1,239)$ & With ASVD $(n=369)$ & Without ASVD $(n=870)$ & $P$ value \\
\hline Age (years) & $75.20 \pm 2.71$ & $75.73 \pm 2.87$ & $74.97 \pm 2.61$ & $<0.001$ \\
\hline Body mass index $(\mathrm{kg} / \mathrm{m} 2)$ & $27.21 \pm 4.68$ & $27.82 \pm 5.29$ & $26.95 \pm 4.38$ & 0.003 \\
\hline Systolic blood pressure $(\mathrm{mm} \mathrm{Hg})$ & $137.76 \pm 18.00$ & $140.73 \pm 18.27$ & $136.54 \pm 17.76$ & $<0.001$ \\
\hline Current smoker (yes/no) & $6(0.0)$ & $3(0.0)$ & $3(0.0)$ & 0.371 \\
\hline Diabetes (yes/no) & $85(6.9)$ & $38(10.3)$ & $47(5.4)$ & 0.002 \\
\hline Prevalent ASVD (yes/no) & $150(12.1)$ & $90(24.4)$ & $60(6.9)$ & $<0.001$ \\
\hline MDRD eGFR $\left(\mathrm{mL} / \mathrm{min} / 1.73 \mathrm{~m}^{2}\right)$ & $65.20 \pm 14.54$ & $62.42 \pm 13.72$ & $66.37 \pm 14.73$ & $<0.001$ \\
\hline CKD-EPI eGFR (mL/min/1.73 $\left.\mathrm{m}^{2}\right)$ & $66.26 \pm 13.47$ & $63.54 \pm 13.76$ & $67.42 \pm 13.19$ & $<0.001$ \\
\hline
\end{tabular}

Results are mean \pm SD or number and (\%). P values are a comparison of those with and without ASVD hospitalizations at 10 years by univariate ANOVA or Chi squared test where appropriate. ASVD atherosclerotic vascular disease, eGFR estimated glomerular filtration rate, MDRD Modification of Diet in Renal Disease and CKD-EPI Chronic Kidney Disease EPIdemiology. 
Table 2 Odds ratios for atherosclerotic vascular disease hospitalizations and mortality by individual variables used in the Framingham risk calculators and eGFR

\begin{tabular}{|c|c|c|c|}
\hline Characteristics $(n=1,239)$ & SD & Odds Ratio $(95 \% \mathrm{Cl})$ & $P$ value \\
\hline Age (years) & 2.71 & $1.32(1.17-1.49)$ & $<0.001$ \\
\hline Body mass index $(\mathrm{kg} / \mathrm{m} 2)$ & 4.68 & $1.20(1.06-1.35)$ & 0.003 \\
\hline Current smoker & yes/no & $2.37(0.48-11.79)$ & 0.292 \\
\hline Diabetes & yes/no & $2.01(1.29-3.14)$ & 0.002 \\
\hline Prevalent ASVD & yes/no & $4.36(3.05-6.20)$ & $<0.001$ \\
\hline Systolic blood pressure $(\mathrm{mm} \mathrm{Hg})$ & 18.00 & $1.26(1.11-1.43)$ & $<0.001$ \\
\hline MDRD eGFR $\left(\mathrm{mL} / \mathrm{min} / 1.73 \mathrm{~m}^{2}\right)$ & 14.54 & $1.34(1.18-1.53)$ & $<0.001$ \\
\hline CKD-EPI eGFR $\left(\mathrm{mL} / \mathrm{min} / 1.73 \mathrm{~m}^{2}\right)$ & 13.47 & $1.34(1.18-1.52)$ & $<0.001$ \\
\hline Framingham risk score 10 -year risk (\%) & 8.58 & $1.45(1.28-1.65)$ & $<0.001$ \\
\hline
\end{tabular}

Results are unadjusted OR (mean $95 \% \mathrm{Cl}$ ) by baseline standard deviation for continuous variables or yes/no for categorical variables. ASVD indicates atherosclerotic vascular disease, eGFR estimated glomerular filtration rate, MDRD Modification of Diet in Renal Disease equation and CKD-EPI Chronic Kidney Disease EPIdemiology equation.

(K/DOQI) and Framingham predicted risk are presented in Figure 1. Individuals with baseline calculated eGFR > than $90 \mathrm{~mL} / \mathrm{min} / 1.73 \mathrm{~m}^{2}$ had a disease free survival of $81 \%$ whereas individuals with an eGFR $<$ than $45 \mathrm{~mL} /$ $\mathrm{min} / 1.73 \mathrm{~m}^{2}$ had a disease free survival of $54 \%$.

Next the Framingham risk score and eGFR calculated by the two methods were examined for independent predictive ability for ASVD risk by inclusion of both variables in the same model to predict ASVD outcomes (Table 3). In each of the comparisons both Framingham risk scores and eGFR calculations per SD were significantly associated with ASVD hospitalization or deaths and the combined hospitalizations and deaths when adjusted for the other value. To put these findings in a clinical context the effect of eGFR on ASVD hospitalization and deaths was calculated using $10 \mathrm{~mL} / \mathrm{min} / 1.73 \mathrm{~m}^{2}$ decreases in eGFR as the unit of change. Analysis of 1,089 participants without ASVD at baseline showed that while the association between eGFR and ASVD hospitalizations and deaths remained significant it was reduced (Figure 2).

The Net Reclassification Improvement (NRI) comparing the 10-year Framingham general cardiovascular risk factors and the MDRD eGFR calculation is shown in Table 4. Using the CKD-EPI eGFR calculation the NRI was $5.1 \% \mathrm{P}=0.040$ and the IDI was $0.015 \pm 0.003$, $\mathrm{P}<0.001$.

\section{Discussion}

These data show a relationship between reduction in eGFR by both the MDRD and CKD-EPI equations and increased long-term ASVD-related hospitalization and mortality in elderly women. This association was independent of the method of calculation of eGFR and analytical approach using either per SD reduction or per $10 \mathrm{~mL} / \mathrm{min} / 1.73 \mathrm{~m}^{2}$ reductions in eGFR. Although slightly diminished by the inclusion of the Framingham
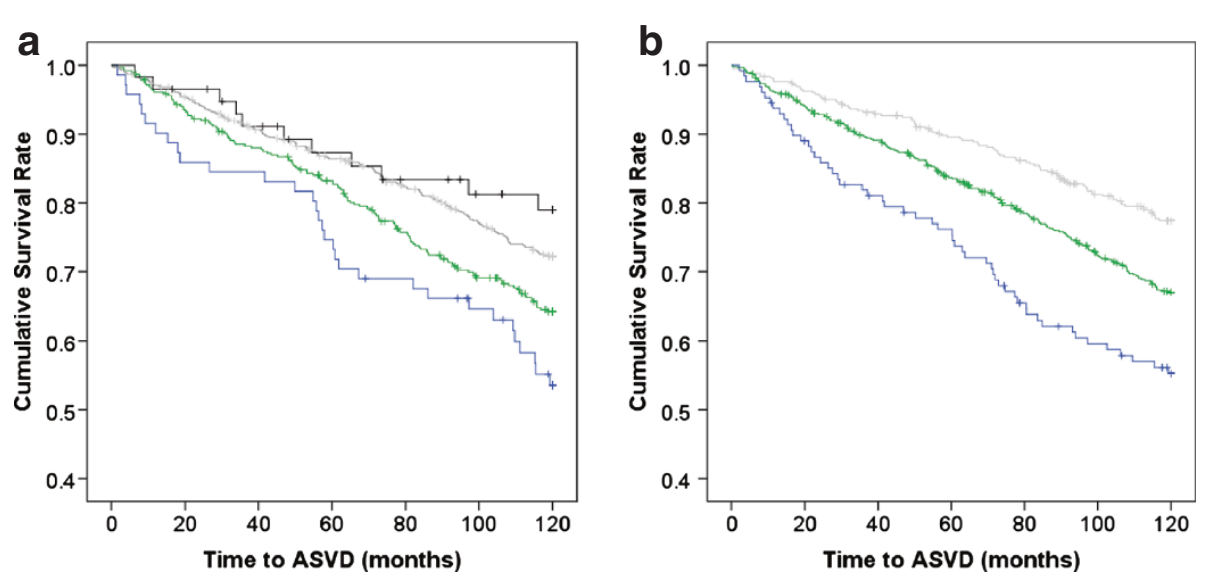

Figure 1 Kaplan Meier survival curves for ASVD hospitalizations and deaths dichotomized by a) K/DOQI chronic kidney disease categories of eGFR by the MDRD equation; blue line $<45 \mathrm{~mL} / \mathrm{min} / 1.73 \mathrm{~m}^{2}(\mathrm{n}=71)$, green line $45-59 \mathrm{~mL} / \mathrm{min} / 1.73 \mathrm{~m} 2(\mathrm{n}=388)$, grey line $60-89 \mathrm{~mL} / \mathrm{min} / 1.73 \mathrm{~m}^{2}(\mathrm{n}=722)$ and black line $\geq 90 \mathrm{~mL} / \mathrm{min} / 1.73 \mathrm{~m}^{2}(\mathrm{n}=58)$ and $\left.\mathrm{b}\right)$ Framingham predicted risk, blue line $\geq 30 \% 10$ year risk $(n=128)$, green line $15-29 \% 10$-year risk $(n=649)$ and grey line $<15 \% 10$-year risk $(n=427)$. 
Table 3 Comparison of eGFR and Framingham risk score in predicting ASVD outcomes in a model including both terms

\begin{tabular}{lcc}
\hline & eGFR & Framingham \\
\hline $\begin{array}{l}\text { ASVD hospitalizations }(\mathbf{n}=\mathbf{3 0 7}) \\
\quad \text { MDRD }\end{array}$ & $1.33(1.15-1.53)$ & $1.48(1.29-1.69)$ \\
$\quad$ CKD-EPI & $1.31(1.15-1.50)$ & $1.47(1.28-1.68)$ \\
ASVD deaths $(\mathbf{n}=\mathbf{1 2 9})$ & & \\
$\quad$ MDRD & $1.29(1.05-1.57)$ & $1.37(1.14-1.64)$ \\
$\quad$ CKD-EPI & $1.32(1.09-1.59)$ & $1.36(1.13-1.63)$ \\
ASVD events $(\mathbf{n}=\mathbf{3 6 9})$ & & \\
$\quad$ MDRD & $1.31(1.14-1.50)$ & $1.43(1.26-1.63)$ \\
CKD-EPI & $1.30(1.15-1.48)$ & $1.43(1.25-1.62)$ \\
\hline
\end{tabular}

The results are odds ratio and $95 \%$ confidence interval per SD decrease in eGFR and per SD increase in Framingham risk score includes age, body mass index, smoking, systolic blood pressure and diabetes. ASVD atherosclerotic vascular disease, eGFR estimated glomerular filtration rate, MDRD Modification of Diet in Renal Disease equation, CKD-EPI Chronic Kidney Disease EPIdemiology equation.

risk models the relationship was not abolished, supporting the concept that renal dysfunction may have its deleterious effect via pathways independent of other traditional risk factors associated with increased ASVD risk [1].

Compared with an elderly woman with an eGFR of $90 \mathrm{ml} / \mathrm{min} / 1.73 \mathrm{~m}^{2}$, an elderly women with eGFR of $60 \mathrm{ml} / \mathrm{min} / 1.73 \mathrm{~m}^{2}$ (currently the reporting level for concern) would be at a $60-63 \%$ increased risk of longterm ASVD-associated hospitalization or death independent of Framingham risk factors. These findings support and extend previous studies showing increased risk in younger patients with an eGFR $60-90 \mathrm{ml} / \mathrm{min} /$ $1.73 \mathrm{~m}^{2}$ [10] . In contrast a recent literature review by Chang and Kramer found eGFR did not significantly improve the C-index in AUC analysis in addition to the Framingham equation [24]. These studies however did not use the newer net reclassification improvement (NRI) or integrated discrimination improvement (IDI) metrics which are designed to evaluate improved predictive ability and are considered to be more powerful than the C-index for comparing predictive models [25]. If addition of variables to a base model improves assignation of individuals to higher or lower probability of having an event the NRI and the IDI value can measure the degree of improvement. The NRI uses clinically

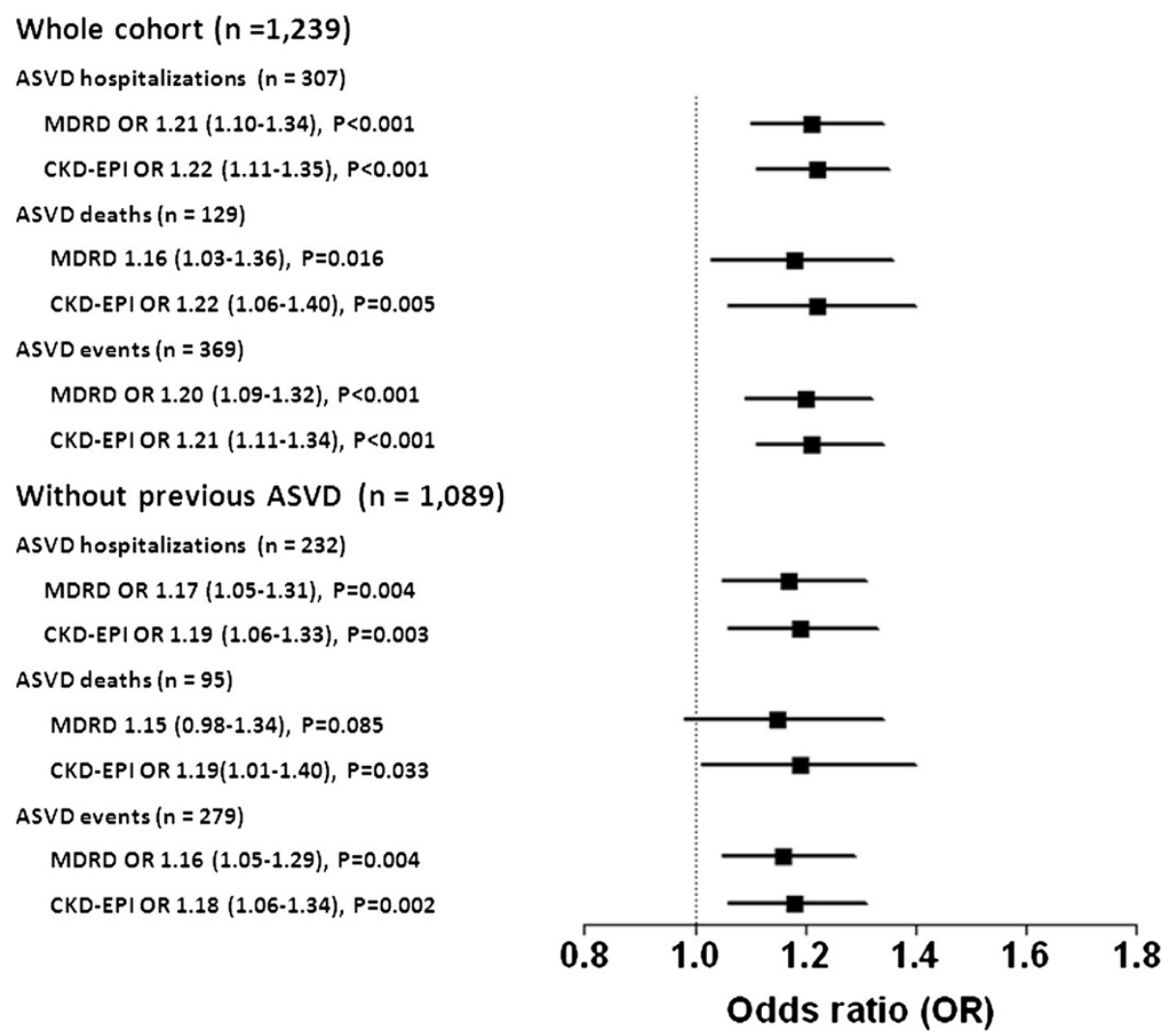

Figure 2 Framingham risk score-adjusted odds ratio and $95 \%$ confidence interval per $10 \mathrm{ml} / \mathrm{min} / 1.73 \mathrm{~m}^{2}$ decrease in eGFR in the whole cohort and those free of ASVD at baseline. ASVD atherosclerotic vascular disease, eGFR estimated glomerular filtration rate, MDRD Modification. 
Table 4 Reclassification among people who do or do not experience an ASVD hospitalization or death during 10-year of follow

\begin{tabular}{|c|c|c|c|c|c|c|}
\hline \multicolumn{7}{|c|}{ Framingham predicted risk with eGFR by MDRD equation } \\
\hline $\begin{array}{l}\text { Framingham predicted } \\
\text { risk without eGFR }\end{array}$ & $<15 \%$ & $15-30 \%$ & $\geq 30 \%$ & $\begin{array}{l}\text { Reclassified } \\
\text { higher risk }\end{array}$ & $\begin{array}{l}\text { Reclassified } \\
\text { lower risk }\end{array}$ & $\begin{array}{c}\text { Correctly } \\
\text { reclassified }\end{array}$ \\
\hline \multicolumn{7}{|c|}{ Participants who experienced ASVD hospitalization or death $(n=352)$} \\
\hline$<15 \%$ & 0 & 3 & 0 & & & \\
\hline $15-30 \%$ & 6 & 124 & 23 & $26(7.4 \%)$ & $23(6.5 \%)$ & $3(0.9 \%)$ \\
\hline$\geq \mathbf{3 0} \%$ & 0 & 17 & 179 & & & \\
\hline \multicolumn{7}{|c|}{ Participants who did not experience ASVD hospitalization or death $(n=852)$} \\
\hline$<15 \%$ & 14 & 9 & 0 & & & \\
\hline $15-30 \%$ & 34 & 439 & 50 & 59 (6.9\%) & $102(12.0 \%)$ & 43 (5.0\%) \\
\hline$\geq \mathbf{3 0} \%$ & 3 & 65 & 238 & & & \\
\hline
\end{tabular}

Net reclassification improvement $(\mathrm{NRI})=5.9 \% \mathrm{P}=0.018, \mathrm{IDI}=0.010 \pm 0.003, \mathrm{P}<0.001$. Framingham risk factors included age, body mass index, smoking, systolic blood pressure and diabetes. ASVD indicates atherosclerotic vascular disease; eGFR estimated glomerular filtration rate and MDRD Modification of Diet in Renal Disease equation.

relevant cut points while the IDI metrics uses risk as a continuous variable. The inclusion of eGFR calculated by either equation added to the Framingham risk factors improved the NRI by between 5.1 to $5.9 \%$. Direct comparisons to other markers of cardiovascular disease are difficult due to the differences in study population demographics, event rates and duration of study however the overall net reclassification improvement is similar to the 5.3\% NRI observed where $\mathrm{C}$ reactive protein and parental history of myocardial infarct was added to traditional cardiovascular risk factors for cardiovascular disease risk prediction [22]. The addition of eGFR to the Framingham risk scores also improved the IDI by 0.010 - 0.015. These results are comparable to those reported in a recent study which found that adding eGFR to other known risk factors improved the IDI by 0.011 [26].

The strengths of this study relate to the complete person-based linkage of the 1,239 participants for all atherosclerotic vascular hospitalizations and mortality using previously validated hospital admission and mortality data from the Western Australian Data Linkage System that has been used in over 250 publications [27] as well as the availability of detailed adverse event data. Limitations of the study are that compared to other studies the sample size is small and is restricted to elderly women. Second the use of serum creatinine, rather than serum cystatin $C$, which has been shown by some [28-31], but not others [32], to be a stronger predictor of all-cause and cardiovascular mortality particularly in older participants. Others have argued that the strong association of cystatin $\mathrm{C}$ with all cause and cardiovascular mortality may be due to its association with factors other than GFR such as measures of body size, diabetes and inflammation [33]. Finally data on the albumin creatinine ratio in these patients was not available a measurement that may add significant predictive data [34].

\section{Conclusion}

In this population impaired renal function is an independent risk for atherosclerotic vascular disease in addition to Framingham risk factors possibly related to age-related structural changes in older kidneys resulting in a reduction in functioning glomeruli.

\section{Abbreviations \\ ASVD: Atherosclerotic vascular disease; CKD: Chronic kidney Disease; CKD- EPI: Chronic Kidney Disease EPIdemiology; eGFR: Estimated glomerular filtration rate; GFR: Glomerular filtration rate; OR: Odds Ratio; K/DOQI: Kidney disease outcomes quality initiative; MDRD: Modification of Diet in Renal Disease Study.}

\section{Competing interests}

The authors have nothing to declare.

\section{Acknowledgements}

The authors wish to thank the staff at the Data Linkage Branch, Hospital Morbidity Data Collection and Registry of Births, Deaths and Marriages for their work on providing the data for this study. The study was supported by Kidney Health Australia grant S07 10, Healthway Health Promotion Foundation of Western Australia and by project grants 254627, 303169 and 572604 from the National Health and Medical Research Council of Australia. None of the funding agencies had any role in the conduct of the study; collection, management, analysis, or interpretation of the data; or preparation, review, or approval of the manuscript. The authors had full access to all of the data in the study and take responsibility for the integrity of the data and the accuracy of the data analysis. The salary of JRL is supported by a Raine Medical Research Foundation Priming Grant.

\section{Author details}

${ }^{1}$ University of Western Australia, School of Medicine and Pharmacology, Sir Charles Gairdner Hospital Unit, Perth, Australia. ${ }^{2}$ Department of

Endocrinology and Diabetes, Sir Charles Gairdner Hospital, Perth, Australia. 3. Department of Renal Medicine, Sir Charles Gairdner Hospital, Perth, Australia. ${ }^{4}$ School of Public Health, Curtin University, Perth, Australia. ${ }^{5}$ Dept. of Cardiovascular Medicine, Sir Charles Gairdner Hospital, Perth, Australia.

\section{Author contribution}

Obtaining funding: JRL, EL, RLP, KZ, WL, conception and design: JL, RLP, WL, data analysis and interpretation - JL, SSD, KZ, RLP, WL and drafting of the manuscript and critical revision: JRL, SSD, EL, RLP, KZ, PLT and WL. All authors' read and approved the final manuscript. 
Relationship with Industry

None

Received: 30 September 2011 Accepted: 16 July 2012

Published: 16 July 2012

\section{References}

1. Go AS, Chertow GM, Fan D, McCulloch CE, Hsu CY: Chronic kidney disease and the risks of death, cardiovascular events, and hospitalization. $N$ Engl J Med 2004, 351(13):1296-1305

2. Levey AS, Stevens LA, Schmid CH, Zhang YL, Castro AF 3rd, Feldman HI, Kusek JW, Eggers P, Van Lente F, Greene T, et al: A new equation to estimate glomerular filtration rate. Ann Intern Med 2009, 150(9):604-612.

3. Ford I, Bezlyak V, Stott DJ, Sattar N, Packard CJ, Perry I, Buckley BM, Jukema JW, de Craen AJ, Westendorp RG, et al: Reduced glomerular filtration rate and its association with clinical outcome in older patients at risk of vascular events: secondary analysis. PLoS Med 2009, 6(1):e16.

4. Matsushita K, van der Velde M, Astor BC, Woodward M, Levey AS, de Jong PE, Coresh J, Gansevoort RT: Association of estimated glomerular filtration rate and albuminuria with all-cause and cardiovascular mortality in general population cohorts: a collaborative meta-analysis. Lancet 2010, 375(9731):2073-2081.

5. Shlipak MG, Fried LF, Cushman M, Manolio TA, Peterson D, Stehman-Breen C, Bleyer A, Newman A, Siscovick D, Psaty B: Cardiovascular mortality risk in chronic kidney disease: comparison of traditional and novel risk factors. JAMA 2005, 293(14):1737-1745.

6. Weiner DE, Tighiouart H, Griffith JL, Elsayed E, Levey AS, Salem DN, Sarnak MJ: Kidney disease, Framingham risk scores, and cardiac and mortality outcomes. Am J Med 2007, 120(6):e551-e558. 552.

7. Parikh NI, Hwang SJ, Larson MG, Levy D, Fox CS: Chronic kidney disease as a predictor of cardiovascular disease (from the Framingham Heart Study). Am J Cardiol 2008, 102(1):47-53.

8. Weiner DE, Tighiouart H, Amin MG, Stark PC, MacLeod B, Griffith JL, Salem DN, Levey AS, Sarnak MJ: Chronic kidney disease as a risk factor for cardiovascular disease and all-cause mortality: a pooled analysis of community-based studies. J Am Soc Nephrol 2004, 15(5):1307-1315.

9. Hemmelgarn BR, Manns BJ, Lloyd A, James MT, Klarenbach S, Quinn RR, Wiebe N, Tonelli M: Relation between kidney function, proteinuria, and adverse outcomes. JAMA 2010, 303(5):423-429.

10. Manjunath G, Tighiouart H, Ibrahim H, MacLeod B, Salem DN, Griffith JL, Coresh J, Levey AS, Sarnak MJ: Level of kidney function as a risk factor for atherosclerotic cardiovascular outcomes in the community. J Am Coll Cardiol 2003, 41(1):47-55

11. Mathew TH, Johnson DW, Jones GR: Chronic kidney disease and automatic reporting of estimated glomerular filtration rate: revised recommendations. Med J Aust 2007, 187(8):459-463.

12. White SL, Polkinghorne KR, Atkins RC, Chadban SJ: Comparison of the prevalence and mortality risk of CKD in Australia using the CKD Epidemiology Collaboration (CKD-EPI) and Modification of Diet in Renal Disease (MDRD) Study GFR estimating equations: the AusDiab (Australian Diabetes, Obesity and Lifestyle) Study. Am J Kidney Dis 2010, 55(4):660-670.

13. Matsushita K, Selvin E, Bash LD, Astor BC, Coresh J: Risk implications of the new CKD Epidemiology Collaboration (CKD-EPI) equation compared with the MDRD Study equation for estimated GFR: the Atherosclerosis Risk in Communities (ARIC) Study. Am J Kidney Dis 2010, 55(4):648-659.

14. Prince RL, Devine A, Dhaliwal SS, Dick IM: Effects of calcium supplementation on clinical fracture and bone structure: results of a 5year, double-blind, placebo-controlled trial in elderly women. Arch Intern Med 2006, 166(8):869-875.

15. Levey AS, Coresh J, Greene T, Marsh J, Stevens LA, Kusek JW, Van Lente F: Expressing the Modification of Diet in Renal Disease Study equation for estimating glomerular filtration rate with standardized serum creatinine values. Clin Chem 2007, 53(4):766-772.

16. Myers GL, Miller WG, Coresh J, Fleming J, Greenberg N, Greene T, Hostetter $T$, Levey AS, Panteghini $M$, Welch $M$, et al: Recommendations for improving serum creatinine measurement: a report from the Laboratory Working Group of the National Kidney Disease Education Program. Clin Chem 2006, 52(1):5-18.
17. K/DOQI clinical practice guidelines for chronic kidney disease: evaluation, classification, and stratification. Am J Kidney Dis 2002, 39(2 Suppl 1):S1S266.

18. D'Agostino RB Sr, Vasan RS, Pencina MJ, Wolf PA, Cobain M, Massaro JM, Kannel WB: General cardiovascular risk profile for use in primary care: the Framingham Heart Study. Circulation 2008, 117(6):743-753.

19. World Health Organization: Manual of the international statistical classification of diseases, injuries, and causes of death: based on the recommendations of the ninth revision conference, 1975, and adopted by the Twenty-ninth World Health Assembly, 1975 revision. edn. Geneva: World Health Organization; 1977.

20. Britt $\mathrm{H}$ : A new coding tool for computerised clinical systems in primary care-ICPC plus. Aust Fam Physician 1997, 26(Suppl 2):S79-S82.

21. World Health Organization: ICD-10: international statistical classification of diseases and related health problems: tenth revision, 2nd edn. Geneva: World Health Organization; 2004.

22. Cook NR, Buring JE, Ridker PM: The effect of including C-reactive protein in cardiovascular risk prediction models for women. Ann Intern Med 2006, 145(1):21-29.

23. Elias-Smale SE, Kavousi M, Verwoert GC, Koller MT, Steyerberg EW, MattaceRaso FU, Hofman A, Hoeks AP, Reneman RS, Witteman JC: Common carotid intima-media thickness in cardiovascular risk stratification of older people: the Rotterdam Study. Eur J Cardiovasc Prev Rehabil 2011, Epub ahead of print.

24. Chang A, Kramer H: Should eGFR and Albuminuria Be Added to the Framingham Risk Score? Chronic Kidney Disease and Cardiovascular Disease Risk Prediction. Nephron Clin Pract 2011, 119(2):C171-c178.

25. Pencina MJ, D'Agostino RB Sr, D'Agostino RB Jr, Vasan RS: Evaluating the added predictive ability of a new marker: from area under the ROC curve to reclassification and beyond. Stat Med 2008, 27(2):157-172. discussion 207-112.

26. Nerpin $E$, Ingelsson $E$, Riserus $U$, Sundstrom J, Larsson A, Jobs E, Jobs M, Hallan S, Zethelius B, Berglund L, et al: The combined contribution of albuminuria and glomerular filtration rate to the prediction of cardiovascular mortality in elderly men. Nephrol Dial Transplant 2011, 26 (9):2820-2827

27. Holman CD, Bass AJ, Rosman DL, Smith MB, Semmens JB, Glasson EJ, Brook $E L$, Trutwein $B$, Rouse IL, Watson CR, et al: A decade of data linkage in Western Australia: strategic design, applications and benefits of the WA data linkage system. Aust Health Rev 2008, 32(4):766-777.

28. Shlipak MG, Sarnak MJ, Katz R, Fried LF, Seliger SL, Newman AB, Siscovick DS, Stehman-Breen C: Cystatin C and the risk of death and cardiovascular events among elderly persons. N Engl J Med 2005, 352(20):2049-2060.

29. Shlipak MG, Katz R, Sarnak MJ, Fried LF, Newman AB, Stehman-Breen C, Seliger SL, Kestenbaum B, Psaty B, Tracy RP, et al: Cystatin C and prognosis for cardiovascular and kidney outcomes in elderly persons without chronic kidney disease. Ann Intern Med 2006, 145(4):237-246.

30. Emberson JR, Haynes R, Dasgupta T, Mafham M, Landray MJ, Baigent C, Clarke R: Cystatin C and risk of vascular and nonvascular mortality: a prospective cohort study of older men. J Intern Med 2010, 268(2):145-154.

31. Menon V, Shlipak MG, Wang X, Coresh J, Greene T, Stevens L, Kusek JW, Beck GJ, Collins AJ, Levey AS, et al: Cystatin C as a risk factor for outcomes in chronic kidney disease. Ann Intern Med 2007, 147(1):19-27.

32. Eriksen BO, Mathisen UD, Melsom T, Ingebretsen OC, Jenssen TG, Njolstad I, Solbu MD, Toft I: Cystatin C is not a better estimator of GFR than plasma creatinine in the general population. Kidney Int 2010, 78(12):1305-1311.

33. Stevens LA, Schmid CH, Greene T, Li L, Beck GJ, Joffe MM, Froissart M, Kusek $J W$, Zhang YL, Coresh J, et al: Factors other than glomerular filtration rate affect serum cystatin C levels. Kidney Int 2009, 75(6):652-660.

34. Warnock DG, Muntner P, McCullough PA, Zhang X, McClure LA, Zakai N, Cushman M, Newsome BB, Kewalramani R, Steffes MW, et al: Kidney function, albuminuria, and all-cause mortality in the REGARDS (Reasons for Geographic and Racial Differences in Stroke) study. Am J Kidney Dis 2010, 56(5):861-871.

\section{doi:10.1186/1471-2369-13-58}

Cite this article as: Lewis et al:: Estimated glomerular filtration rate as an independent predictor of atherosclerotic vascular disease in older women. BMC Nephrology 2012 13:58. 